\title{
DEVELOPMENT OF TAMPING ARM OF MULTIPURPOSE TAMPING MACHINE FOR INDIAN RAILWAY
}

\section{MANAS PANDEY ${ }^{1} \&$ P. SUDHAKAR RAO ${ }^{2}$}

${ }^{1}$ Student, Department of Mechanical Engineering, National Institute of Technical Teachers Training and Research,

\author{
Chandigarh, India
}

${ }^{2}$ Assistant Professor, Department of Mechanical Engineering, National Institute of Technical Teachers Training and Research,

Chandigarh, India

\begin{abstract}
As indicated by railroad spending plan 2019, Indian rail line have evaluated the expense of Rs 2700 crore for rail line wellbeing and rail line upkeep, it implies that the rail route is giving first concern to mishap avoidance measures. Packing process is most significant upkeep process. In this way in reference with the examination the above writing audit is finished. Based on above writing survey following are the ends: The Indian railroad needs to diminish its reliance on manual support. Indian railroad is picking the most recent innovation to fix the equivalent. Since the bought packing machines are a lot of expensive Due to German standard innovations and imposing business model of Plasser and Theurer in packing machine advertise in most extreme nations of the world. In this way India began taking a shot at Indigenization of Tamping machines to lessen the expense of packing machine. : This paper gives the new structure and Investigation of Tamping Arm for Indigenized Multipurpose Tamping Machine for Indian Railway.

KEYWORDS: Maintenance, Technology, Tamping, Machine, 3D Modelling, Analysis, Indigenization \& Cost Reduction
\end{abstract}

Received: Jun 10, 2020; Accepted: Jun 30, 2020; Published: Jul 25, 2020; Paper Id.: IJMPERDJUN2020457

\section{INTRODUCTION}

With the adaptation of indigenized components in its complicated assembly of track tamping machine, it is very much feasible and practicable to improve the quality similar to imported tamping units for trouble free service to ensure the optimum utilization of costlier traffic block.

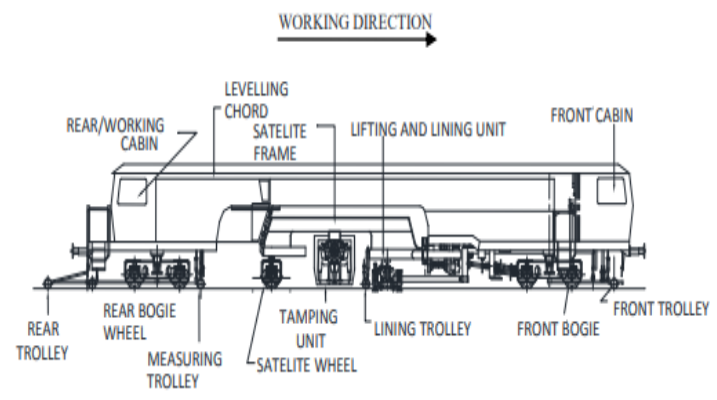

Figure 1.1: Tamping Machine [1].

When the total Tamping unit gets entered beneath the base of the sleeper, crushing activity happens to fill the 
voids and to press the balance through packing devices.

Indian railway board has selected the development of tamping unit for tamping express.

The tamping arms are centrally hinged links between squeezing cylinder and Tamping tools. Vibration generated by hydraulic motor passes to Tamping tools through these Tamping arms. It fills two fundamental needs. Right off the bat, moving the vibration to Tamping instruments which makes ease in stabilizer to encourage smooth infiltration in ballasted tracks for packing activities. Besides, it gets turned inside for pressing capacity after augmentation of water driven chamber mounted with vibration shaft.

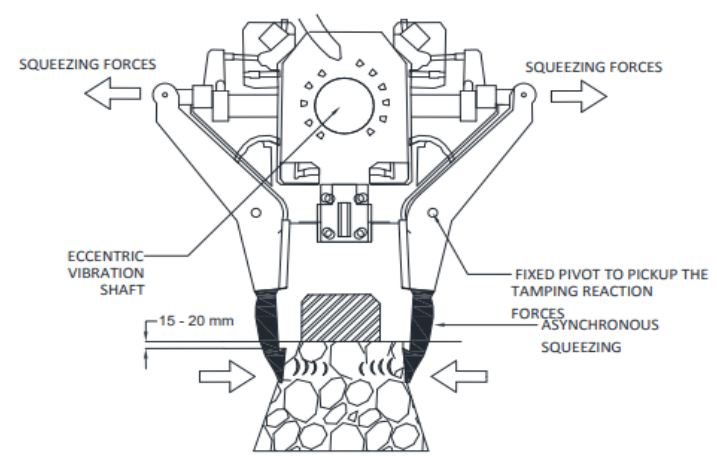

Figure 1.2: Multi-Purpose Tamping Unit.

\section{EXISTING TAMPING ARM DESIGN}

Since this tamping arm is mounted on tamping gear box over central location and rotating in phosphorus bronze bush as a lever mechanism, its performance is mostly concerned with the smooth moment of sleeve inside the bush. A taper bore has been designed in existing version for fitment of tamping tools in tamping arms.

Due to taper design in bore, it gets elongated and resulting in loosening of Tamping tools. It has another constraint in design that during every replacement of Tamping tool, it requires an upward hammering action for fitment of the tool.

This hammering effect leads to damage of center pin bush (phosphorus bronze bush) and in turn, pre mature ovality takes place. Once excessive play is created over center arm

Bush, amplitude of vibration increases and causing the excessive vibration and noise in tamping unit. This excessive vibration leads to pre mature breakage of bearings, cylinders, arms etc.

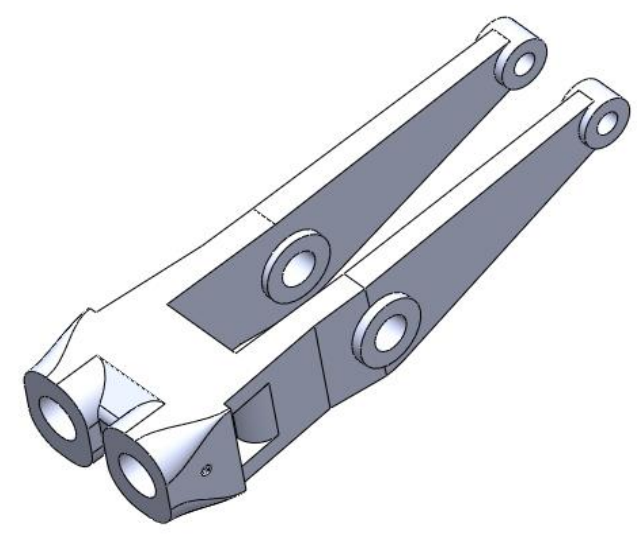


Figure 1.3: Tamping arm with Tapered Bore.

\section{NEW TAMPING ARM DESIGN FOR MULTI PUROSE TAMPING MACHINE}

So as to limit the formation of play over focus arm shrub, change in structure of Tamping apparatus installation is watched and considered. A straight bore holding unit rather than tighten held on for development and flexibility based bolting course of action has been changed as a medicinal measure. Aftereffects of progress in apparatus fixing course of action is now demonstrated in Tamping unit of Tamping express Machine and had worked easily.

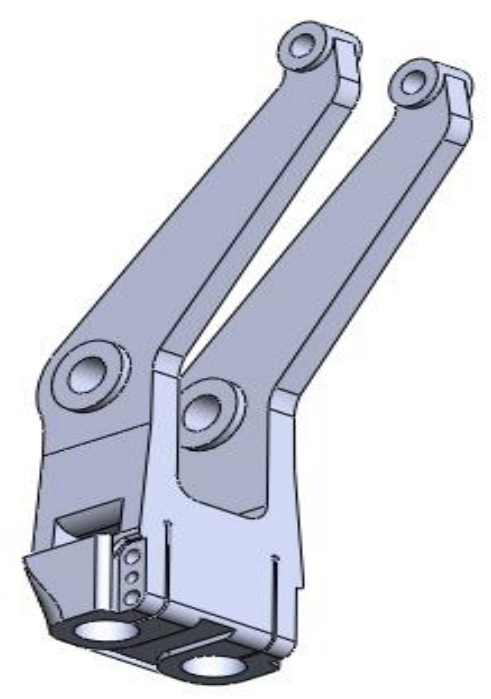

Figure 1.4: Tamping Arm with Straight Tool Bore.

Development of Tamping unit for multipurpose Tamping machine, arm design of straight bore mounting system is proposed.

\section{NET LOAD ON TAMPING ARM}

On the basis of above diagram one could easily understand the various load acting on the Tamping Arm, on the basis of these load, Stress Analysis Analysis of the Tamping Arm is completed.

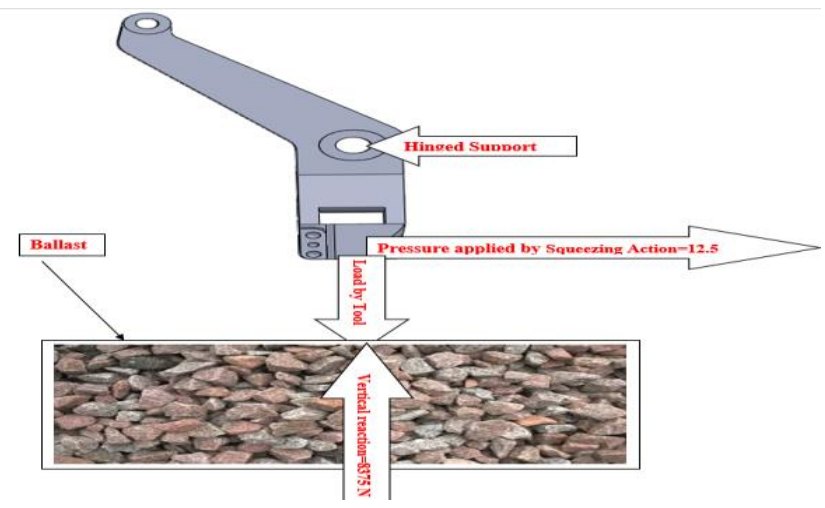

Figure 3.1: Diagram of Load Applied on ARM.

As discussed earlier that:

Squeezing Pressure = 125 Bar (Generally varies from 115 Bar to 125 Bar $)$ 
Net mass of a MPT unit $=\mathbf{8 0 0} \mathbf{k g}$

Therefore Weight of a MPT unit=800×9.81

$=7848 \mathrm{~N}$

Since whole Tamping Unit moves downwards For the Tamping action by a pressure applied by central Hydraulic cylinder. Therefore Net Hydraulic pressure through which Whole unit is moving Downwards $=\mathbf{1 2 0 K g} / \mathbf{c m}^{2}$

As we know that $1 \mathrm{~kg} / \mathrm{cm}^{2}=\mathbf{9 8 0 6 6 . 5}$ Pascal

So $120 \mathrm{Kg} / \mathrm{cm}^{2}=11767980$ Pascal

Since the diameter of central hydraulic cylinder is $(\mathrm{d})=\mathbf{8 0} \mathbf{m m}$

Therefore Area of Piston Of central Hydraulic Cylinder $A=\pi r^{2}$

$$
=\frac{\pi}{4} \times 08 \times 08
$$

$=0.005027 \mathrm{~m}^{2}$

Therefore, force acting downwards $=\mathbf{P} \times \mathbf{A}$

$=59145.87 \mathrm{~N}$

Net Load Acting Downwards = force acting downwards+ Weight of a MPT unit

$=\mathbf{7 8 4 8}+\mathbf{5 9 1 4 5 . 8 7}$

$=66993.87 \mathrm{~N}$

Since in a MPT Unit There are total Eight no of Tamping Tools.

Therefore Net load will be distributed on all Eight tools $=\mathbf{6 6 9 9 3 . 8 7} \mathbf{N}$

So Net downward Load on One Tool will be $=\mathbf{6 6 9 9 3 . 8 7} \div 8$

Net downward Load on One Tool $=8374.93$ N $\mathbf{8 3 7 5}$ N

$=8375 \mathrm{~N}$

On the basis of the data provided by the Railway Track Machine CPOH Prayagraj, the value of net Load Acting on The Tamping Arm calculated. From Analysis point of view Two data, First the squeezing Pressure And second The net Downward Load Applied by Tamping Arm on the Ballast is needed which Has been calculated above.

\section{COMPARISON BETWEEN TAPERED TOOL BORE AND STRAIGHT TOOL BORE TAMPING ARM DESIGNS}

When the same load applied on both tamping arms, the tamping arm with Tapered tool performed better than the straight tool bore tamping arm on Ansys workbench.

Following are the inferences drawn from the analysis- 

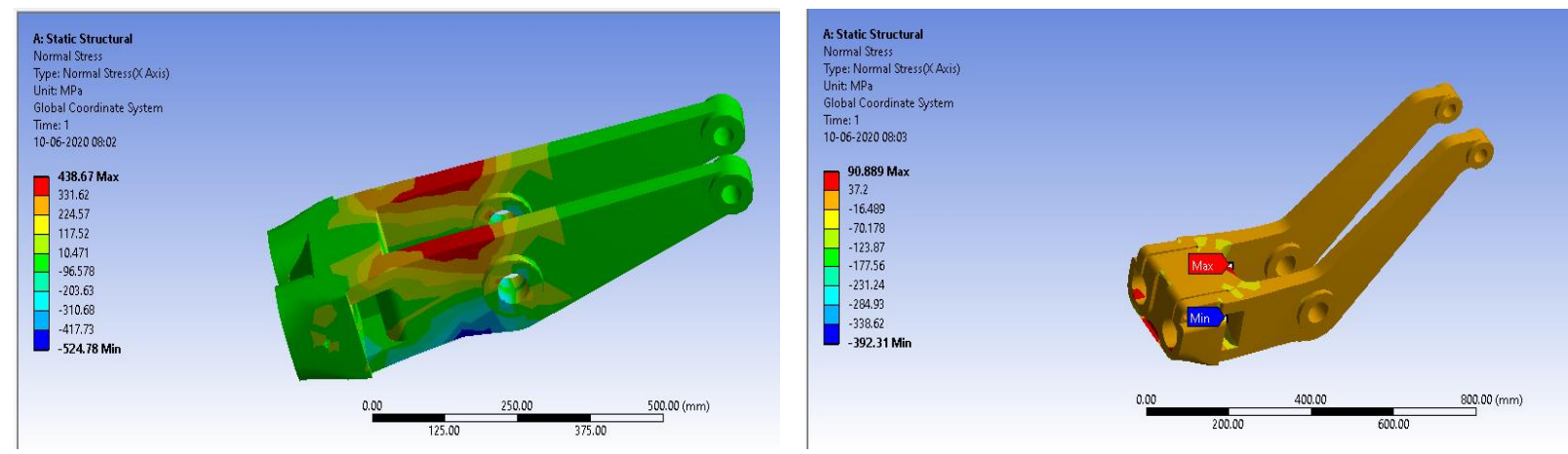

Figure 1.4: Normal Stress Analysis.
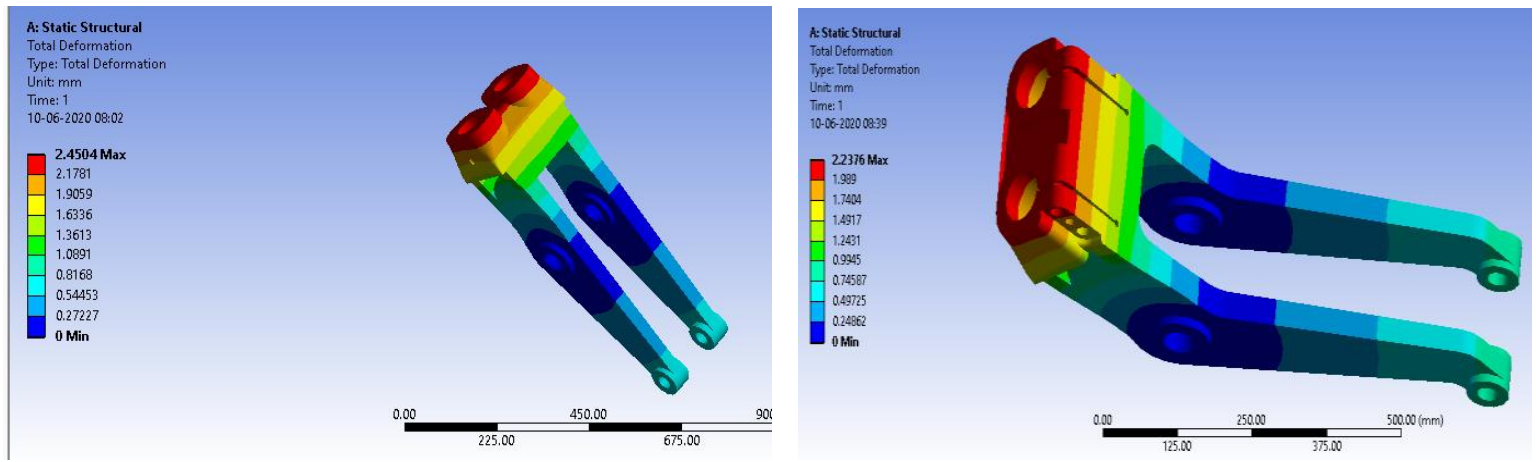

Figure 1.5: Total Deformation.

On the basis of above analysis it is clear that tamping arm with straight tool is having less total deformation and less normal stress than the tapered tool bore tamping arm.

\section{RESULTS AND DISCUSSIONS}

It is expected that by development of Tamping arm with this modification will lead to drastic improvement in Service life of Tamping unit as there would be no upward hammering action required for fixing of tool in this design. Side bolts will expand the tool bore after tightening to facilitate easy fixing of tools and once side bolts are released, Tamping arm will grip the Tamping tools with the elasticity of the material. There is no possibility of expansion of tool bore in this new proposed design of tamping arm.

Table.2: Cost Analysis of Tamping Unit

\begin{tabular}{|c|l|c|c|}
\hline Sl. No. & \multicolumn{1}{|c|}{ Name of the Machine } & Purchased Machine Cost & Indigenized Machine Cost \\
\hline 1. & Multipurpose tamping machine & 450 lakh & $30 \mathrm{Lakh}$ \\
\hline 2. & Tamping arm & $15 \mathrm{Lakh}$ & $4 \mathrm{Lakh}$ \\
\hline
\end{tabular}

Table 3:life Cycle Analysis of Tamping Unit

\begin{tabular}{|c|l|c|c|}
\hline $\begin{array}{c}\text { Sl. } \\
\text { No. }\end{array}$ & Name of the Machine & $\begin{array}{c}\text { Approx. life of } \\
\text { Purchased Machine } \\
\text { Cost }\end{array}$ & $\begin{array}{c}\text { Approx. Life of } \\
\text { Purchased Machine } \\
\text { Cost }\end{array}$ \\
\hline 1. & $\begin{array}{l}\text { Multipurpose tamping } \\
\text { machine }\end{array}$ & $1500 \mathrm{~km}$ & $1000 \mathrm{~km}$ Expected \\
\hline
\end{tabular}

\section{CONCLUSIONS}

Now the Track and machine Central Periodic Overhauling Workshop North Central Railway Division Allahabad Is Starting 
Work on Project “Design and Development of Indigenized Multipurpose Tamping Machine.

This would be a great achievement and will create a way to promote make In India programme.

\section{REFERENCES}

1. V.K. Agnihotri, “Revised Indian Railways Track machine manual.” Railway Board, New Delhi, Second Edition, IRTMM; 2017.

2. T. N. Ramachandran, "Indian Railway Permanent way Manual.” 2004.

3. www.plasserindia.com

4. www.plassertheurer.com

5. Prakash, D. Surrya, et al. "A review on latest development of aluminium alloy metal matrix composite through powder metallurgy route." International Journal of Mechanical and Production Engineering Research and Development 2018: 235-241.

6. Indian Railway, "Review on Procurement and Utilization of Track Machines in Indian Railways.” Report No.24, volume II of Railway; 2015.

7. Chavan, Amrita B., and K. Rajeswari. "The design and developement of decentralized digilocker using blockchain." International Journal of Computer Science Engineering and Information Technology Research (IJCSEITR) 9 (2019): 29-36.

8. Indian Railways Institute of Civil Engineering, “Mechanized Tamping and stabilization.” Pune, India. November 2016.

9. Padiya, S. A. G. A. R., Rakesh Pandit, and Sachin Patel. "Survey of innovated techniques to detect selfish nodes in Manet." IJCNWMC 3.1 (2013): 221-230.

10. Research Designs and Standards Organisation, "List of specification and drawing." Manaknagar, Lucknow, India. December 2019.

11.Kaur, H. A. R. P. R. E. E. T., J. A. S. P. A. L. Singh, and SATINDER KAUR Khattra. "The workability and compressive strength of concrete using textile mill sludge and plasticizer." I Jl Civil, Structural, Environl Infrastructure Eng Research Dev 7 (2017): $1-8$.

12.Plasser and Theurer, “Ballast tamping machine." Practical Hints and Regulations for Tamping Works Vienna, Austria. September, 1984.

\section{AUTHORS PROFILE}

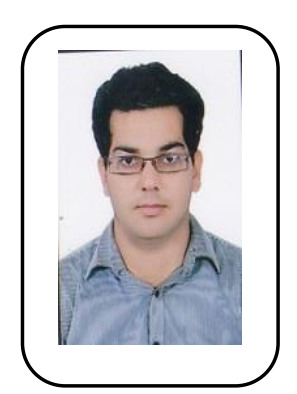

Manas Pandey completed degree from APJ Abdul Kalam Technical University Lucknow, Uttar Pradesh in Mechanical Engineering. Presently pursuing M.E. in Manufacturing Technology at NITTTR, Chandigarh India. Key areas of 
research interest includes Engineering design, CAD/CAM.

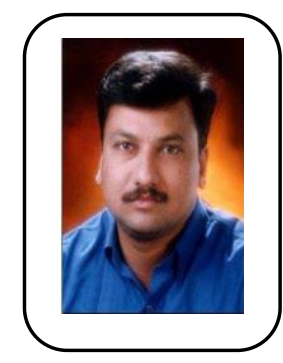

Dr. P. Sudhakar Rao Assistant Professor in Mechanical Engineering Department, NITTTR, Chandigarh. He completed his Ph.D. from IIT Roorkee. A key area of his research interest includes advanced micro-machining, CAD/CAM/CIM, Engineering Materials, and RPT/RE. 
